\title{
What do the translator and the grocery shopper have in common? Well, everything!
}

\author{
H. Pierre Hsieh
}

School of History , UCC

\section{Introduction}

What would be the first thing that comes to your mind if I told you I was a translator? Chances are it would be "mediator", "negotiator" or "communicator" if you have had prior dealings with the academic field of translation studies, or it would be "copycat", "impersonator", "plagiarist" or "cribber" if you have never even heard of translation studies. More specifically, what if I told you I was a legal translator? Chances are it would be more or less the same thing, only this time around you would probably be grappling with what to make of the term legal (Well, does it mean "concerning the law in general" or does it mean "legitimate"?) All this indicates the low prestige that is accorded to works of translation and the disrespect for translators that the lay public has. How did it come to this, and does it have to be this way? The way I see it, this is the case because scientifically rigorous research on translation as a social phenomenon and human activity has not been pursued satisfactorily, and hence, translation studies must now carry on in a systematic and scientific way.

\section{Translation Theory}

What is translation theory and why does translation even need a theory at all? Should it all not be rather straightforward? Paradoxically, at the same time, many translators wonder why translators and their work have rarely, if ever, been taken seriously. The truth is most people will have some dealings with translation at some point in their lives. Who can claim that they have never enjoyed a short story or a fairy tale-either on paper or on film—by a foreign author that had to be translated into their native language? Who has never played a video game that was imported and had to be translated and/or localized? And who has never travelled overseas and had to obey a sign that required the imagination of some translator? However, as it turns out, if a translation is terrible, then it is the translator that is to blame; if it appears successful, then it is the author-not the translator-that gets the credit. In other words, damned if you do and damned if you don't. Given how widespread, necessary and ubiquitous translation is, why the low prestige and the guilt associated with it? 
The reasons may be many, but my simple answer to it is that translation has never earned due respect because it was never properly associated with people's everyday lives, and academia still has a long way to go. More to the point, true, laypeople, uninitiated as they are, may have the wrong idea about translators by considering them little more than someone reciting a text that they themselves have hardly made any contribution to, but translation theorists, who have seriously devoted themselves to the true nature of translation for decades, must share the blame. Please do not get me wrong; by no means am I suggesting that translation theorists like James Holmes, Anthony Pym and Maria Tymoczko have achieved nothing; it goes without saying that they have made great contribution to human knowledge by coming up with various ways of describing the translation phenomenon, and, yet, the thing is, it appears to me that their efforts may not have gone far enough. Indeed, thanks to the discipline-wide tacit understanding that translation studies is inherently interdisciplinary as it deals with a phenomenon that requires the expertise from a myriad of established disciplines, translation theorists have taken advantage of sociological methodology_and quite successfully for that matter-and have thereby benefited greatly from it. This is promising, but much as I agree that translation must be studied as a social activity in the context of sociology, sociology alone will probably not be sufficient to make translation resonate with the lay public-and with good reason.

Our world is dynamic and ever-changing, with robust changes occurring every day that attract the attention of social scientists. While sociologists look at human behaviour their own way, economists approach it in a totally different light, usually by identifying values that matter and assigning each of them a numeric value (quantification). While, to a great extent, interviewing and fieldwork constitute the cornerstone of sociology, economics deals with quantified values presented in the form of equations, matrices and mathematical expressions. Admittedly, each comes with its unique strengths and hard-toovercome weaknesses.

At the heart of the argument is the process of theory construction-translation theory to be exact. Translation studies is, by definition, the academic scholarship that is responsible for the development of translation theories. While the word translation itself rarely conjures up a romantic image among the lay public, which tends to regard the translator as nothing but a "copycat" or, worse yet, a traitor — as the witty and frivolous saying Traduttore, traditore, (literally, "the translator, the traitor") goes there is actually more to it than meets the eye. People often inadvertently fail to realize that the translator is as much a human being made of flesh and blood as anyone else and that translation is no less a human activity than anything else. More specifically, human beings, emulative and gregarious as they are, are social creatures who live and survive in societies that impose norms on them whether they like it or not. This is probably inevitable for collective life to be possible and also for "the greater good". At the same time, they are economic creatures in that they are rational and self-interested and have their agendas to pursue; they know what is in their best interest and how to achieve it, despite their occasional ignorance of the related risks 
their action entails and the potential impact it has on others (externalities). This is, as a matter of fact, a fundamental aspect of human nature that has served as the driving force behind human civilization since time immemorial.

On this view, from the sociological perspective, the translator is a social being who must, either consciously or subconsciously, comply with all prevalent social norms (and by "norms" I mean everything from morals to bylaws and regulations) of the day, and so, as a quick example, if the term queer (to denote "homosexual") is not socially acceptable in that it may evoke negative sentiments among the target readership, or worse yet, allure the watchful eyes of the censor, then it should be best avoided by the translator. This approach does have its merits, except that it only captures one dimension of translation by viewing it as a social phenomenon. On the other hand, translation does have an economic dimension to it, and in this context, the economist may prefer to approach it from an economic perspective by viewing it as an economic activity involving a host of quantifiable values. Arguably, these two conspicuously unrelated perspectives can and will work hand-in-hand towards a fuller and more complete picture of translation.

In the eyes of the economist, every individual is both rational and self-interested insofar as they are acting within the limits of the information available to them. They are selfinterested (or self-serving or selfish, as some prefer in the sense that they are aware of what is optimal for them-and for them only, and they are rational in that they understand how to achieve that interest. Thus, for the sake of illustration, the consumer and grocery shopper will take only their own interest into consideration when struggling to make up their mind what consumer product to buy (Is it going to be apples, carrots or onions on the dinner table?) and where to buy it (Say, Tesco, Aldi or Lidl, anyone?) based on the information available to them (How long will it take to get there? And will the checkout queue likely be long?). While generating the optimal choice, will they consider what someone else would like to have for dinner? Probably not. And will they do what they think is right for themselves? Yes, of course. And so is there a subtle, hidden and unspoken rule or logic to it? Definitely. And would it be possible to approach and describe that logic that is so intangible and yet so powerful nonetheless descriptively and quantitatively? Absolutely!

The same thing goes for translation. The translator, forced to make repeated choices and decisions throughout the lengthy process of rendering terms, phrases, sentences and other lexical units into the target language, is expected to strike a fine balance between making the original text accessible to a new audience and maintaining its essential foreignness and originality, as well as a delicate balance amongst a wide range of mutually conflicting values. For instance, when confronted with the phrase Le Québec et le Canada, should the translator just translate it literally as "Quebec and Canada" or, perhaps out of some political finesse or in deference to unspeakable peer pressure, paraphrase it as "Quebec and the rest of Canada"? Whichever version the translator eventually goes with, the pos- 
sible values behind their choice could have been personal ideology, profitability, physical length, typesetting, rhythm, personal preference, editor's preference, and consistency, just to name a few, each of which may be subject to quantification, while, in the meantime, the potential costs would include risk of offending the target readership, risk of unfaithfulness to the author as well as (possibly) censorship, all of which, again, could avail of quantification. And how is this any different from the math and arithmetic that the grocery shopper has to go through?

\section{Conclusion}

Thus, I firmly believe that there is little difference between the translator and the consumer and shopper. The truth is, when a consumer purchases groceries, they understand what they need (interests) and what their budget is (resources), and on top of that they are aware how to achieve what they want (rationality). Different supermarkets may have dissimilar prices and merchandises, but they also have different store hours and distinct locations (information). There are always hidden costs (overheads) involved, as there may be potential side effects (externalities) entailed, which will then lead to the optimal decision (maximum profit). All these factors, which are to be taken into consideration and then subjected to calculation, are comparable to what the translator has to deal with in their line of duty. It may not seem obvious prima facie, but translators are usually confronted with an overwhelmingly large amount of factors ranging from what saves time, what wins the audience's attention, what pleases the publisher, and what will get past the censors... when making up their mind how to render a phrase from the source language into another language. Seen in this light, all human activity is economic in nature, be it voting in an election, alcohol consumption, white-collar crime or translation. As long as translation is considered a human activity, its description should utilize economic analysis, and human experiences derived from consumer behaviour will serve as a powerful and useful example on this score. Nothing may sound more straightforward, but few in translation studies realize that translation, as a human activity, can have something so economic going for it.

This is truly a shame, for if translation theorists and translators themselves all noticed that, not only would it help theorists ascertain the true nature of translation, translation would also appear closer and more relevant to people's bread and butter. This will unquestionably give the status of professional translators a boost, which will, in turn, urge more competent bilingual and multilingual individuals to enter the translation industry and provide more translation works for the general readership at large.

As two human activities, translation and consumption share a host of common traits; this includes, among others, rationality, self-interestedness, profit maximization and ethics. First off, the translator, just like the grocery shopper, is self-interested in the sense that they pay attention to nothing but what they can get out of it, and even if they appear altruistic 
from time to time, they are eventually doing it to their advantage. In pursuing their goal, the translator makes choices that produce benefits and gains for themselves, serving their own interest. Second of all, the translator, just like the grocery shopper, is rational in the sense that he understands how to achieve his very self-serving and egocentric goals. When handling a domain-specific term, they may have to consult an expert for advice, a dictionary or a terminology bank, just as a consumer would go bargain hunting for the goods and services and ask around for the perfect price. Thirdly, the translator is a profit maximizer in the sense that they will always work with a built-in "calculator" that does the math for them by adding up all the pros (monetary gain, reputation, fame and pecuniary interest...) and deducting all the cons (risks, censorship, time and other forms of monetary expenses...). Last but not least, just as there are ethics involved in sales and purchases (Must the seller disclose every minor detail about the merchandise to the buyer?), there will always be baffling ethical issues involved in translation as to, inter alia, how faithful the translator should be vis-à-vis the author, if and how much the translation should be allowed to deviate from the original, and whether it is acceptable to add one's own remarks and comments to a translation.

See how simple it all is! The translator and the grocery shopper have everything in common, because they are both simply you and me-people who are trying to make tough choices and hard decisions. At the end of the day, no matter what industry we find ourselves in, we are all trying to make the best choices for ourselves with whatever limited resources and information available to us. Since economics is good at explaining all this, it will, alongside sociology, have a great deal to offer translation studies, and as such, it will undoubtedly make translators more respectable and translated works more approachable to the general public, which will, in turn, remind people to start affording translators and their works the awe and respect they deserve. 